\title{
A review of surgical strategies for penile prosthesis implantation in patients with Peyronie's disease
}

\author{
James Anaissie, Faysal A. Yafi \\ Department of Urology, Tulane University School of Medicine, New Orleans, LA 70112, USA \\ Contributions: (I) Conception and Design: FA Yafi; (II) Administrative support: FA Yafi; (III) Provision of study materials or patients: FA Yafi; (IV) \\ Collection and Assembly of data: All authors; (V) Data analysis and interpretation: All authors; (VII) Manuscript Writing: All authors; (VIII) Final \\ approval of manuscript: All authors. \\ Correspondence to: Faysal A. Yafi. Department of Urology, Tulane University Health Sciences Center, 1430 Tulane Ave. 86-42, New Orleans, LA \\ 70112, USA. Email: fyafi@tulane.edu.
}

\begin{abstract}
The introduction of the inflatable penile prosthesis (IPP) has revolutionized the treatment of patients with both Peyronie's disease (PD) and erectile dysfunction (ED). A thorough literature review was performed in order to review the surgical strategies used to treat PD, using the PubMed online database with the keywords "penile prosthesis", "surgical management" and "Peyronie's disease". Patient satisfaction rates of $72-100 \%$ and partner satisfaction rates of $89 \%$ have been reported in the literature, although strong preoperative education may be needed to prepare patients for risks such as penile shortening, seen in up to $54 \%$ of patients. Three-piece IPPs are most commonly used, and when comparing the two most popular models (AMS $700 \mathrm{CX} v$ s. Coloplast Titan), no significant differences were seen in functional outcomes or patient satisfaction. Simple insertion of an IPP has been shown to resolve curvature in 33-90\% of patients, but surgeons may often need to also utilize ancillary straightening procedures for residual curvatures. Manual modeling can correct residual curvature with an $86-100 \%$ success rate, but with a $4 \%$ risk of urethral injury. When the post-modeling residual curvature exceeds 30 degrees, a plaque-releasing incision or plication is recommended to further reduce curvature. Grafting is recommended if the resulting incisional defect is larger than two centimeters. Alternative straightening techniques such as plication prior to IPP insertion, endoscopic plaque resection, the "scratch technique" and bone saw plaque incision have also been described.
\end{abstract}

Keywords: Incision and grafting; manual modeling; Peyronie's disease (PD); penile prosthesis; tunical plication

Submitted Jan 15, 2016. Accepted for publication Mar 09, 2016.

doi: $10.21037 /$ tau.2016.04.04

View this article at: http://dx.doi.org/10.21037/tau.2016.04.04

\section{Introduction}

Peyronie's disease (PD) is a physically and emotionally taxing condition. During the initial, or acute phase, the disease is accompanied by pain and the progression of penile curvature (1). The chronic phase signals the end of inflammation and stabilization of penile curvature and fibrosis, usually occurring within 12-18 months of disease onset (2). The development of erectile dysfunction (ED) in association with PD is also commonly seen, possibly due to plaque disruption of cavernosal blood flow (3).
Surgical management should be implemented for patients who have reached the chronic phase, with a plaque that has been stable for at least 3-6 months with resolution of pain. Furthermore, surgery is indicated if medical management has failed, the deformity prevents optimal sexual intercourse, the penile plaque is extensive, or if a patient with stable disease desires rapid results $(1,3-6)$. A multitude of surgical options exist for the treatment of PD, including Nesbitt and other modified plications, plaque incision/partial excision and grafting, and implantation of a penile prosthesis (PP) (7). 
Table 1 Key studies on intraoperative curvature management with penile prosthesis for Peyronie's disease

\begin{tabular}{|c|c|c|c|c|c|c|c|c|}
\hline Study, year & Patients & $\begin{array}{l}\text { Mean follow-up } \\
\text { (months) }\end{array}$ & $\begin{array}{c}\text { IPP } \\
\text { alone (\%) }\end{array}$ & $\begin{array}{l}\text { Modeling } \\
\text { alone (\%) }\end{array}$ & $\begin{array}{c}\text { Incision/plication } \\
\text { alone (\%) }\end{array}$ & $\begin{array}{l}\text { Grafting } \\
\text { alone (\%) }\end{array}$ & $\begin{array}{c}\text { Satisfaction } \\
(\%)\end{array}$ & $\begin{array}{c}\text { Revisions } \\
\text { (\%) }\end{array}$ \\
\hline Levine et al. 2000 (7) & 25 & 39 & $-{ }^{*}$ & 54 & 28 & 18 & - & 0 \\
\hline Chaudhary et al. (18) 2005 & 46 & 42 & 39 & 61 & - & - & 93 & 4 \\
\hline Levine et al. (8) $2010^{\dagger}$ & 90 & 49 & 4 & 79 & 4 & 12 & 46 & 13 \\
\hline
\end{tabular}

${ }^{*}$, IPP insertion always accompanied by modeling as per study protocol; ${ }^{\star *}$, Modeling not used due to risk of urethral injury; ${ }^{\dagger}$, this study included the use of semirigid IPPs. IPP, Inflatable penile prosthesis.

PP implantation is recommended for patients with $\mathrm{PD}$ and medication-refractory ED (3,7-10). It is also the most popular method for the management of $\mathrm{PD}$. A nationwide US survey showed that $75 \%$ of practicing urologists who operate for PD choose to do so via PP implantation (11). Continuous advancements in the field have resulted in PP technology having one of the lowest mechanical failure rates of any device implanted in humans (12), with success rates ranging between $86 \%$ and $100 \%(7,8,13-15)$. Patients who have tried both oral therapy and injections also favor PP (16).

One of the major factors for success in PP implantation is the intraoperative management of residual curvature (Table 1). While successful curvature correction can be achieved with PP cylinder placement alone, there may be a need for further intraoperative straightening procedures in up to $61 \%$ of cases (17). One study showed that while preoperative curvatures $\leq 30^{\circ}$ often did not necessitate additional procedures, the need for interventions increased to $12 \%$ for curvatures of $31^{\circ}-45^{\circ}$, to $75 \%$ for curvatures of $45^{\circ}-60^{\circ}$, and up to $100 \%$ for those curvatures that were $>60^{\circ}$ $(9,20)$. The aim of this manuscript is to review the current literature on the strategies for PP placement in patients with PD.

\section{Methods}

A thorough literature review was performed in order to review the surgical strategies used to treat Peyronie's disease, using the PubMed online database with the keywords "Penile Prosthesis", "surgical management", and "Peyronie's disease" (from 1975 to December 2015). Database searches resulted in 913 potentially relevant articles, and 86 articles were chosen for review in the manuscript. Randomized trials were included, as well as nonrandomized controlled trials, cohort studies, and relevant reviews when randomized trials were not available.

\section{Pre-operative education}

Comprehensive patient education is crucial prior to $\mathrm{PP}$ implantation, and may help maximize post-operative patient satisfaction. Patients with $\mathrm{PD}$ and ED who are being evaluated for a penile prosthesis may have unrealistic goals for the procedure's outcome, and managing their expectations should be a priority $(21,22)$. Overall, patient satisfaction rates of $72-100 \%$ and partner satisfaction rates of $89 \%$ have been reported in the literature (18,19,23-26). Patients with PD have been found to have significantly lower International Index of Erectile Function (IIEF)erectile function scores than the general PP population, and less of a postoperative improvement in the IIEF satisfaction domain (21). Dissatisfaction has been linked to shortened penile size, reduced sensitivity, poor concealment, and device deviation (27).

The most common complaint in men who undergo PP placement is penile length loss, reported in up to $54 \%$ of patients postoperatively (8). Although the loss in length does not generally impair function, the majority of men with PD already have baseline penile shortening, making any additional loss due to surgery very distressing $(1,28,29)$. A study examining patient satisfaction two years after PP placement showed that $30 \%$ of patients were dissatisfied with penile length, and $25 \%$ of their sexual partners were not completely satisfied (30). Less common complications include infections (3-9\%), mechanical failure (7\%), persistent curvature (4\%), hypoesthesia and paresthesia $(2 \%)$, erosion $(2 \%)$, and difficulties using and deflating 
the device (1\%) $(8,17,23,31-35)$. Repeat surgery for PP revisions or replacements are reported to range between $6 \%$ and $13 \%$, most commonly due to mechanical failure $(8,26)$.

Informed consent and patient counseling are usually performed as a one-on-one discussion, but other methods may also be effective, such as watching a prerecorded video, education over several visits, or connecting PP candidates with other PP patients who can share their postoperative experiences (36). Penile duplex Doppler ultrasound can also be performed to provide a baseline objective assessment, which can be used for postoperative comparison. Proper informed consent also has implications for the physician, as studies have shown that litigation surrounding PP implantation in the US involves providing suboptimal informed consent in $31 \%$ of cases for a mean indemnity award of over $\$ 800,000$ to the plaintiff (37).

\section{Surgical technique}

In 1973, the use of PP to treat ED, and later PD, gained popularity with the advent of the semi-silicone prosthesis (38). Later, the development of the inflatable penile prosthesis (IPP), an improvement upon the semi-rigid or malleable devices, led to higher patient satisfaction and lower implant malfunction rates (39-43).

However, the first type of PP to be used was the silicone semi-rigid prosthesis. This prosthesis does not change in size, but the position is memorized, allowing the prosthesis to stay rigid only during sexual intercourse to allow penetration. While it is generally believed that semi-rigid prostheses are cheaper and easier to implant due to the lack of a pump and a reservoir (44), a new study actually showed a significantly longer OR time when placing a semi-rigid device when compared to an IPP (45). While semi-rigid prostheses are still used, they have mostly fallen out of favor due to poorer patient satisfaction, higher residual curvature, and less success with intraoperative curvature correction rates when compared to their IPP counterpart (46). In one study, a 5 -year follow-up showed that only $48 \%$ of PD patients treated with semi-rigid PP and $40 \%$ of their partners were completely satisfied and would repeat the procedure, and penile deformity was still persistent in $12 \%$ of cases (27). Patients cited development of a "pencil-like" penis, diminished sensation, poor concealment, and penile deformity as primary reasons for their dissatisfaction. Their partners complained of poor penile girth, cold glans, and a sensation of unnatural coitus and dyspareunia. In another study, penile curvature persisted up to one year after surgery in $35 \%$ of patients (47). Intraoperative manual modeling, or forceful bending of the penis in the direction opposite to the curvature, may correct persistent curvature (39). With the semi-rigid PP however, manual modeling results in much lower rates of success when compared to modeling with an IPP. In one study, success rates of $90 \%$ were seen with manual modeling with an IPP, compared to only $54 \%$ success with the semi-rigid model (19). Although the literature demonstrates disadvantages to the semirigid prostheses, as of 2008 they were still preferred for the treatment of PD by up to $12 \%$ of practicing urologists, according to a nationwide survey (11).

Advantages of the IPP device include ability to conceal $(91 \%)$, ease of inflation (84\%), lack of difficulty with deflation (71\%), and higher partner satisfaction (8). There are both two- and three-piece types of IPP. Placement can be performed through penoscrotal, infrapubic or subcoronal incision, with approximately $80 \%$ of practicing urologists preferring the former (11). The two-piece models are composed of the cylinders in the corpora cavernosa and a pump located in the scrotum (26). This design can compromise erections because the reservoir volume is limited. In the three-piece models, a third reservoir component with additional fluid reserve is placed in the abdominal cavity. Traditionally, the reservoir has been placed in the prevesical or retropubic space, also known as the space of Retzius. Although complications are rare, risk of viscous or vascular injury has led some prosthetic surgeons to believe placement in an "ectopic" location, such as anterior or posterior to the transversalis fascia, is advantageous to patient safety (48-50).

Many types of three-piece IPPs are available for use today. When comparing the AMS $700 \mathrm{CX}$ (American Medical Systems, Minneapolis, MN, USA) to the Coloplast Titan (Coloplast, Minneapolis, MN, USA), no significant differences in functional outcomes or patient satisfactions were observed (26). These models led to patient satisfaction rates between $86 \%$ and $91 \%$, with a $6 \%$ revision rate. When comparing various AMS 700 models, the AMS 700 CX cylinders were found to be superior to AMS Ultrex cylinders, due to less post-operative mechanical buckling and residual curvature $(6,39)$. Further studies of the Ultrex cylinders showed that intraoperative modeling may lead to aneurismal dilatation or an S-shaped deformity $(51,52)$. Newer generation AMS 700 CX models with parylene coating minimize cylinder wear, and have shown improved mechanical reliability (42). As such, with regards to selection of an IPP device, the AMS 700 CX and Coloplast 


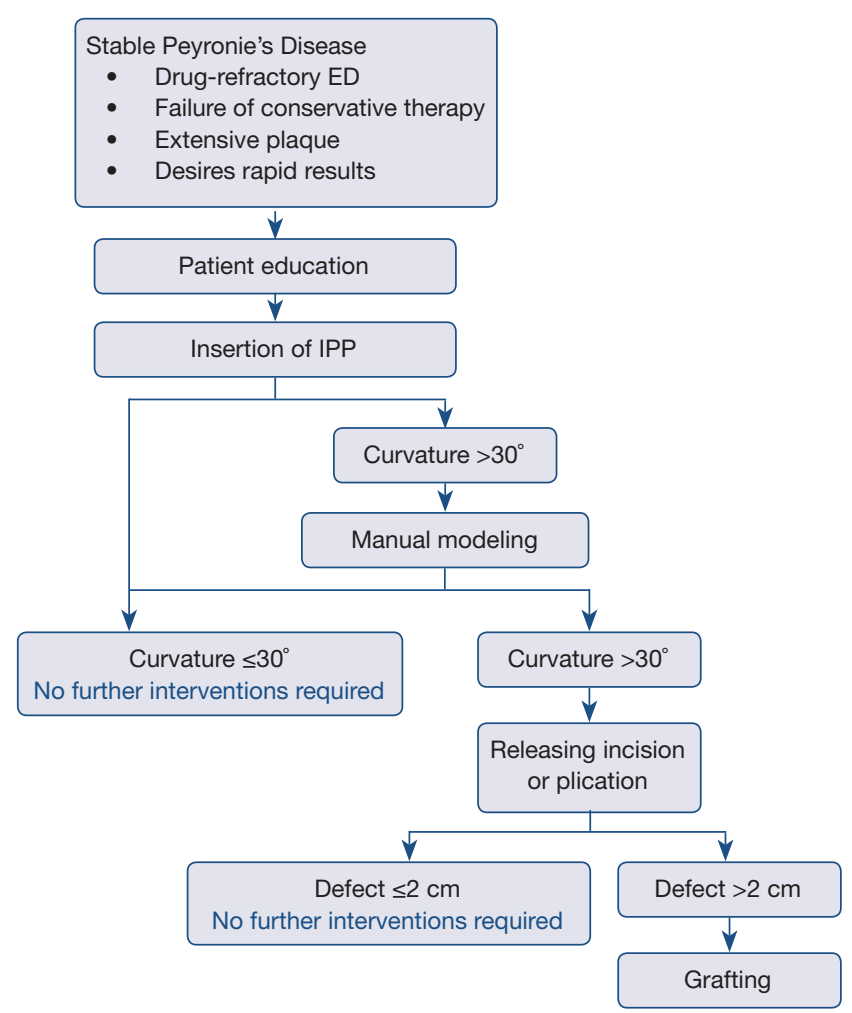

Figure 1 Outcomes following implantation of inflatable IPP in Peyronie's disease. IPP, inflatable penile prosthesis.

Titan are considered equally effective and superior to the AMS 700 Ultrex, and presumably its successor, the AMS 700 LGX $(6,26,45)$.

Penile curvature can be corrected by simple insertion of an IPP, without further intraoperative alteration, although the literature reports mixed results. In one study, satisfactory correction of curvature was achieved in just $4 \%$ of patients with IPP insertion alone, with the rest requiring additional interventions (8). Most reports, however, have shown that IPP insertion can correct curvature with success rates between $33 \%$ and $90 \%(6,17-19,26,53-55)$. One study showed that IPP insertion led to complete resolution of penile curvature in $67 \%$ in all patients with $30^{\circ}-60^{\circ}$ preoperative deformity, but in no patients who had preoperative curvature $>60$ (17). In those with residual curvature after IPP insertion, a commonly adopted surgical algorithm $(1,7,9,10,53)$ is often used for additional intraoperative straightening, as illustrated in Figure 1.

As previously described, the complications of IPP insertion include loss of penile length, infection, diminished sensitivity, and mechanical failure. The most feared complication, however, is IPP infection, with an incidence ranging from $3-9 \%(17,34,43,56,57)$, and as high as $22 \%$ in a 5-year follow-up study of IPP insertion in Europe (58). Diabetes mellitus has been suggested as a key risk factor for developing an IPP infection $(32,57,59)$. If an infection does occur, all components of the implant must be removed (18). A Mulcahy salvage procedure can be performed, in which the IPP is removed, the wound is thoroughly irrigated, and the device is replaced with a malleable prosthesis in the same sitting (60). When studied, 54 out of 58 patients (93\%) remained infection-free after the salvage procedure, and 17 (31\%) elected to later switch back to an IPP, on average 6.7 months after the Mulcahy salvage (61).

\section{Manual modeling}

When IPP insertion alone does not sufficiently correct penile curvature, manual modeling is the next step to reduce residual curvature $(1,7,17,19,20,62,63)$. Most studies have shown that between $10 \%$ and $61 \%$ of patients with PD may need additional straightening procedures after simple IPP implantation (6,17-19,26,53,54). Introduced in 1994 by Wilson and Delk, modeling is now the predominant method used for further penile straightening during IPP placement $(11,64)$.

Manual modeling involves inflating the prosthesis and forcibly bending and holding it in the opposite direction of the curvature in order to rupture the fibrotic plaques $(64,65)$. First, rubber shods should be applied to the tubing between the pump and the cylinders. The penis is then bent in the contralateral direction of the curvature, and held in this position for 90 seconds. This process is repeated twice, until residual curvature is $<30^{\circ}$.

In Wilson and Delk's original study on manual modeling, the authors demonstrated that modeling can correct residual curvature with an $86 \%$ success rate (64). A follow-up study with 30 patients cited a success rate of $80 \%$ (38), and further research with patients receiving AMS 700 CX implants showed a $100 \%$ curvature correction rate after modeling (39). Similar success rates have since been replicated $(7,66)$. Notably, 5-year follow-up studies showed a similar incidence of device revision when compared to men whose IPP implantation was performed without manual modeling (42).

One reported complication of modeling is urethral injury. In the Wilson and Delk series on manual modeling, a $4 \%$ rate of urethral perforation was reported, compared to none in those without modeling, most likely due to distal displacement of the cylinders into the meatus (64). A 4\% urethral injury rate has been confirmed in most studies 
and was not lowered by limiting the number of modeling sessions $(26,42,67)$. To reduce the likelihood of urethral injury, it is suggested to place the bending hand on the shaft of the penis, as opposed to the glans, with the other hand firmly holding pressure down over the corporotomies $(1,20,42,64)$.

\section{Incision or plication}

While modeling is highly successful in adjusting residual curvature after IPP insertion, many authors have reported significant residual curvature in $20-30 \%$ of patients that required additional surgery (68). When post-modeling residual curvature exceeds $30^{\circ}$, most algorithms recommend a plaque-releasing incision or plication to further reduce the curvature $(1,7,19,20,62,69,70)$. A releasing incision is a lengthening procedure, such that a dissection made in the fibrotic plaque of the tunica albuginea overlying the area of maximum curvature lengthens the concave side of the penis. Plication, on the other hand, involves placing sutures on the longer (convex) part of the penis in order to shorten it so that it matches the other side, thus correcting curvature. Although it is recommended to begin with modeling, a 2008 survey of urologists showed that almost one third of physicians choose plaque incisions to manage persistent curvature in excess of $30^{\circ}$ after IPP placement, without preliminary modeling (11). Alternatively, a technique to reduce urethral injury has been suggested which involves plication prior to IPP insertion. Studies have shown complete curvature correction with this technique, but with penile shortening in up to $73 \%$ of patients (71).

Plaque incisions were needed for curvature correction following manual modeling in just $8 \%$ of patients when Wilson and Delk first described their modeling technique (64). When performing plaque incision, Buck's fascia and the neurovascular bundle are elevated and the cylinders are deflated to allow for a tunical incision. The cylinders are then re-inflated, and the surgeon can proceed with further modeling (20). In a trial in which the outcomes of plaque incision to correct residual curvature (without modeling) were studied, complete straightening in $95 \%$ of patients was observed at 35 months (72).

Penile plication has also been shown to be an effective means of curvature reduction, often when residual curvature is more severe (70). In a study using plication to correct curvature before IPP insertion, all 15 enrolled patients had a reduction in curvature from a mean of $39^{\circ}$ to less than $5^{\circ}$ with no postoperative complications, although 11 patients
(73\%) reported decreased penile length $(68,73)$. An advantage of plication when compared to plaque incision is enhanced rigidity and sensation, and fewer palpable nodules (74). An obvious disadvantage is loss of penile length.

\section{Grafting}

Plaque-releasing incisions can result in defects, often necessitating tunical grafting. Although no standard exists, it is recommended that an incisional defect $>2 \mathrm{~cm}$ be corrected with a graft to prevent cicatrix contracture or herniation of the prosthesis $(8,9,20)$. Some experts have recommended incision-excision and grafting in men with penile curvature $>60^{\circ}$ or with large dorsal or ventral plaques ( $>4 \mathrm{~cm}$ ) after manual modeling (75).

Traditionally, synthetic grafting material has been used, but biografts are currently the standard of care. Dermal skin grafts were first available in 1974, followed by grafts of the saphenous vein $(76,77)$, with initially promising results. These have since fallen out of favor because they only contain one surface available for absorption, and have a higher risk for bacterial infections $(6,7,46)$. Currently recommended biograft materials include autologous rectus fascia, cadaveric pericardium, and porcine submucosal intestinal substance (SIS) (64). Some experts suggest that autologous rectus fascia may have an added advantage, as the procedure does not require an additional incision if a suprapubic incision is made for IPP insertion (65). Additionally, satisfactory sexual intercourse has been reported in $93-100 \%$ of patients $(78,79)$.

For all graft materials, it is important to ensure tailoring the graft material to a size approximately $25 \%$ larger than the size of the defect, in order to allow for penile extension and graft contraction (51). A relatively new technique based on geometric principles during an erection has been developed in order to maximize the precision of graft preparation $(29,80)$. Using this technique, a satisfaction rate of $89 \%$ and a $3.6-\mathrm{cm}$ mean functional gain in penile length have been reported, although three patients $(2.9 \%)$ developed graft retraction and residual curvature $(29,81)$. The involved calculations are, however, tedious (20). Another grafting strategy, the "sliding technique" achieves simultaneous penile lengthening via ventro-dorsal incision of the tunica albuginea, stretching of the penis, IPP insertion, and double dorsal-ventral patch grafting with porcine small intestinal submucosa (82). When studied, all three patients resumed sexual intercourse without complications, with an average $3.2 \mathrm{~cm}$ increase in penile length. Alterations to this 
approach have led to the modified sliding technique (MoST), which consists of the previously described sliding method, but with closure of the newly created tunical defect with only Buck's fascia, thus avoiding the need for grafting $(83,84)$. At 10 months of follow-up, mean IIEF scores increased from 24 at baseline to 60 postoperatively, along with an average penile length gain of $3.1 \mathrm{~cm}$.

\section{Other described techniques}

Alternative transcorporal techniques have been developed in an attempt to reduce the need for extensive modeling, incision, plication, and grafting. Some of these include the transcorporal incision, the "scratch" technique, and the use of a tissue-protecting bone saw for ossified plaque incision $(14,85,86)$.

With the transcorporal incision, PD plaques are incised with the assistance of a cystoscope introduced into the corpora cavernosa through a penoscrotal incision. Corporal length is then measured, and cylinder implantation proceeds in a normal fashion. In a study of 16 patients, all had complete straightening of the penis after 14 months without sensory deficits or residual curvature, resumed sexual activity, and an average increase of $2.1 \mathrm{~cm}$ in penile length (14).

The "scratch" technique is an attempt to minimize the risk of urethral injury reported with manual modeling (85). After the point of maximum curvature is detected via artificial erection, a nasal speculum is passed through the infrapubic corporotomy incision, and a scalpel or scissors are inserted internally to "scratch" or scrape, the plaque. The IPP is then implanted in normal fashion, and manual modeling may be performed if necessary (62). To date, no clinical trials have been published using the "scratch" technique.

Finally, in order to further break down ossified PD plaques that cannot be cut with a blade, a novel technique has been developed which utilizes a soft tissue-protecting bone saw for plaque incision (86). In this technique, a blade scalpel is used to incise the plaque to the calcification, at which point the bone saw is used to make transverse incisions through the entirety of the ossified plaque down to the cavernous tissue. The procedure is followed by either IPP placement (without subsequent modeling) or grafting. In a study of 100 patients with $\mathrm{PD}$, six had ossified plaques that required the use of a bone saw for incision (86). Four of those six patients underwent grafting procedures with porcine SIS and two underwent placement of IPP after plaque incision. There were no surgical complications. Both
IPP patients had functioning prostheses four and seven years after surgery, while one SIS-graft patient required reoperation.

\section{Conclusions}

A successful IPP implantation for PD requires a managing of patients' expectations to help them to understand the procedure's benefits and risks. Simple insertion of an IPP can result in functional straightness in a large number of patients, but additional procedures such as manual modeling, incisions and plication, and grafting are often needed to achieve functional straightening of penile curvature.

\section{Acknowledgements}

None.

\section{Footnote}

Conflicts of Interest: The authors have no conflicts of interest to declare.

\section{References}

1. Levine LA, Burnett AL. Standard operating procedures for Peyronie's disease. J Sex Med 2013;10:230-44.

2. Mulhall JP, Schiff J, Guhring P. An analysis of the natural history of Peyronie's disease. J Urol 2006;175:2115-8; discussion 2118.

3. Ralph D, Gonzalez-Cadavid N, Mirone V, et al. The management of Peyronie's disease: evidence-based 2010 guidelines. J Sex Med 2010;7:2359-74.

4. Levine LA, Larsen SM. Surgery for Peyronie's disease. Asian J Androl 2013;15:27-34.

5. Kendirci M, Hellstrom WJ. Critical analysis of surgery for Peyronie's disease. Curr Opin Urol 2004;14:381-8.

6. Segal RL, Burnett AL. Surgical Management for Peyronie's Disease. World J Mens Health 2013;31:1-11.

7. Levine LA, Dimitriou RJ. A surgical algorithm for penile prosthesis placement in men with erectile failure and Peyronie's disease. Int J Impot Res 2000;12:147-51.

8. Levine LA, Benson J, Hoover C. Inflatable penile prosthesis placement in men with Peyronie's disease and drug-resistant erectile dysfunction: A single-center study. J Sex Med 2010;7:3775-83.

9. Mulhall J, Anderson M, Parker M. A surgical algorithm for men with combined Peyronie's disease and erectile 
dysfunction: functional and satisfaction outcomes. J Sex Med 2005;2:132-8.

10. Levine LA, Lenting EL. A surgical algorithm for the treatment of Peyronie's disease. J Urol 1997;158:2149-52.

11. Shindel AW, Bullock TL, Brandes S. Urologist practice patterns in the management of Peyronie's disease: a nationwide survey. J Sex Med 2008;5:954-64.

12. Wilson SK, Delk JR, Salem EA, et al. Long-term survival of inflatable penile prostheses: single surgical group experience with 2,384 first-time implants spanning two decades. J Sex Med 2007;4:1074-9.

13. Austoni E, Colombo F, Romano AL, et al. Soft prosthesis implant and relaxing albugineal incision with saphenous grafting for surgical therapy of Peyronie's disease: a 5-year experience and long-term follow-up on 145 operated patients. Eur Urol 2005;47:223-9; discussion 229.

14. Shaeer O. Trans-corporal incision of Peyronie's plaques. J Sex Med 2011;8:589-93.

15. Grasso M, Lania C, Fortuna F, et al. Preservation of cavernosal erectile function after soft penile prosthesis implant in Peyronie's disease: long-term followup. Adv Urol 2008;646052.

16. Rajpurkar A, Dhabuwala CB. Comparison of satisfaction rates and erectile function in patients treated with sildenafil, intracavernous prostaglandin E1 and penile implant surgery for erectile dysfunction in urology practice. J Urol 2003;170:159-63.

17. Mulhall J, Ahmed A, Anderson M. Penile prosthetic surgery for Peyronie's disease: defining the need for intraoperative adjuvant maneuvers. J Sex Med 2004;1:318-21.

18. Chaudhary M, Sheikh N, Asterling S, et al. Peyronie's disease with erectile dysfunction: penile modeling over inflatable penile prostheses. Urology 2005;65:760-4.

19. Garaffa G, Minervini A, Christopher NA, et al. The management of residual curvature after penile prosthesis implantation in men with Peyronie's disease. BJU Int 2011;108:1152-6.

20. Yafi FA, Sangkum P, McCaslin IR, et al. Strategies for penile prosthesis placement in Peyronie's disease and corporal fibrosis. Curr Urol Rep 2015;16:21.

21. Akin-Olugbade O, Parker M, Guhring P, et al. Determinants of patient satisfaction following penile prosthesis surgery. J Sex Med 2006;3:743-8.

22. Berger RE. Remodeling for Peyronie's disease with implants. Contemp Urol 1995;7:45-8, 53, 55-6 passim.

23. Carson CC, Levine LA. Outcomes of surgical treatment of Peyronie's disease. BJU Int 2014;113:704-13.
24. Tornehl CK, Carson CC. Surgical alternatives for treating Peyronie's disease. BJU Int 2004;94:774-83.

25. DiBlasio CJ, Kurta JM, Botta S, et al. Peyronie's disease compromises the durability and component-malfunction rates in patients implanted with an inflatable penile prosthesis. BJU Int 2010;106:691-4.

26. Chung E, Solomon M, DeYoung L, et al. Comparison between AMS $700 \mathrm{CX}$ and Coloplast Titan inflatable penile prosthesis for Peyronie's disease treatment and remodeling: clinical outcomes and patient satisfaction. J Sex Med 2013;10:2855-60.

27. Montorsi F, Guazzoni G, Bergamaschi F, et al. Patientpartner satisfaction with semirigid penile prostheses for Peyronie's disease: a 5-year followup study. J Urol 1993;150:1819-21.

28. Wang R, Howard GE, Hoang A, et al. Prospective and long-term evaluation of erect penile length obtained with inflatable penile prosthesis to that induced by intracavernosal injection. Asian J Androl 2009;11:411-5.

29. Egydio PH, Kuehhas FE, Sansalone S. Penile length and girth restoration in severe Peyronie's disease using circular and longitudinal grafting. BJU Int 2013;111:E213-9.

30. Montorsi F, Guazzoni G, Barbieri L, et al. AMS 700 CX inflatable penile implants for Peyronie's disease: functional results, morbidity and patient-partner satisfaction. Int J Impot Res 1996;8:81-6.

31. Cakan M, Demirel F, Karabacak O, et al. Risk factors for penile prosthetic infection. Int Urol Nephrol 2003;35:209-13.

32. Carson CC. Diagnosis, treatment and prevention of penile prosthesis infection. Int J Impot Res 2003;15 Suppl 5:S139-46.

33. Lotan Y, Roehrborn CG, McConnell JD, et al. Factors influencing the outcomes of penile prosthesis surgery at a teaching institution. Urology 2003;62:918-21.

34. Mulcahy JJ. Surgical management of penile prosthesis complications. Int J Impot Res 2000;12 Suppl 4:S108-11.

35. Wilson SK, Delk JR 2nd. Prevention and treatment of complications of inflatable penile prosthesis surgery: a review article. Arch Esp Urol 1996;49:306-11.

36. Trost LW, Baum N, Hellstrom WJG. Managing the difficult penile prosthesis patient. J Sex Med 2013;10:893906; quiz 907.

37. Sunaryo PL, Colaco M, Terlecki R. Penile prostheses and the litigious patient: a legal database review. J Sex Med 2014;11:2589-94.

38. Raz S, Dekernion JB, Kaufman JJ. Surgical treatment of Peyronie's disease: a new approach. J Urol 1977;117:598-601. 
39. Montague DK, Angermeier KW, Lakin MM, et al. AMS 3 -piece inflatable penile prosthesis implantation in men with Peyronie's disease: comparison of CX and Ultrex cylinders. J Urol 1996;156:1633-5.

40. Subrini L. Surgical treatment of Peyronie's disease using penile implants: survey of 69 patients. J Urol 1984;132:47-50.

41. Eigner EB, Kabalin JN, Kessler R. Penile implants in the treatment of Peyronie's disease. J Urol 1991;145:62-9.

42. Wilson SK, Cleves MA, Delk JR 2nd. Long-term followup of treatment for Peyronie's disease: modeling the penis over an inflatable penile prosthesis. J Urol 2001;165:825-9.

43. Carson CC. Penile prosthesis implantation in the treatment of Peyronie's disease. Int J Impot Res 1998;10:125-8.

44. Ateia AH, Voinescu O, Geavlete R. Penile prosthesis in the surgical treatment of Peyronie's disease. J Med Life 2012;5:280-2.

45. Henry GD, Karpman E, Brant W, et al. The Who, How and What of Real-World Penile Implantation in 2015: The PROPPER Registry Baseline Data. J Urol 2016;195:427-33.

46. Zaid UB, Alwaal A, Zhang X, et al. Surgical management of Peyronie's disease. Curr Urol Rep 2014;15:446.

47. Ghanem HM, Fahmy I, el-Meliegy A. Malleable penile implants without plaque surgery in the treatment of Peyronie's disease. Int J Impot Res 1998;10:171-3.

48. Karpman E, Sadeghi-Nejad H, Henry G, et al. Current opinions on alternative reservoir placement for inflatable penile prosthesis among members of the Sexual Medicine Society of North America. J Sex Med 2013;10:2115-20.

49. Stember DS, Garber BB, Perito PE. Outcomes of abdominal wall reservoir placement in inflatable penile prosthesis implantation: a safe and efficacious alternative to the space of Retzius. J Sex Med 2014;11:605-12.

50. Perito PE. Ectopic reservoir placement--no longer in the space of Retzius. J Sex Med 2011;8:2395-8.

51. Carson CC. Penile prosthesis implantation in the treatment of Peyronie's disease and erectile dysfunction. Int J Impot Res 2000;12 Suppl 4:S122-6.

52. Wilson SK, Cleves MA, Delk JR 2nd. Ultrex cylinders: problems with uncontrolled lengthening (the S-shaped deformity). J Urol 1996;155:135-7.

53. Ralph DJ, Minhas S. The management of Peyronie's disease. BJU Int 2004;93:208-15.

54. Pryor J, Akkus E, Alter G, et al. Peyronie's disease. J Sex Med 2004;1:110-5.

55. Porena M, Mearini L, Mearini E, et al. Penile prosthesis implantation and couple's satisfaction. Urol Int 1999;63:185-7.

56. Tunuguntla HS. Management of Peyronie's disease--a review. World J Urol 2001;19:244-50.

57. Wilson SK, Delk JR 2nd. Inflatable penile implant infection: predisposing factors and treatment suggestions. J Urol 1995;153:659-61.

58. Natali A, Olianas R, Fisch M. Penile implantation in Europe: successes and complications with 253 implants in Italy and Germany. J Sex Med 2008;5:1503-12.

59. Wilson SK, Wahman GE, Lange JL. Eleven years of experience with the inflatable penile prosthesis. J Urol 1988;139:951-2.

60. Mulcahy JJ. Long-term experience with salvage of infected penile implants. J Urol 2000;163:481-2.

61. Gross MS, Phillips EA, Balen A, et al. The Malleable Implant Salvage Technique: Infection Outcomes after Mulcahy Salvage Procedure and Replacement of Infected Inflatable Penile Prosthesis with Malleable Prosthesis. J Urol 2016;195:694-8.

62. Lyons MD, Carson CC 3rd, Coward RM. Special considerations for placement of an inflatable penile prosthesis for the patient with Peyronie's disease: techniques and patient preference. Med Devices (Auckl) 2015;8:331-40.

63. Serefoglu EC, Hellstrom WJ. Treatment of Peyronie's disease: 2012 update. Curr Urol Rep 2011;12:444-52.

64. Wilson SK, Delk JR 2nd. A new treatment for Peyronie's disease: modeling the penis over an inflatable penile prosthesis. J Urol 1994;152:1121-3.

65. Kadioglu A, Akman T, Sanli O, et al. Surgical treatment of Peyronie's disease: a critical analysis. Eur Urol 2006;50:235-48.

66. Usta MF, Bivalacqua TJ, Sanabria J, et al. Patient and partner satisfaction and long-term results after surgical treatment for Peyronie's disease. Urology 2003;62:105-9.

67. Montorsi F, Salonia A, Maga T, et al. Reconfiguration of the severely fibrotic penis with a penile implant. J Urol 2001;166:1782-6.

68. Mulcahy JJ, Wilson SK. Management of Peyronie's disease with penile prostheses. Int J Impot Res2002;14:384-8.

69. Adibi M, Hudak SJ, Morey AF. Penile plication without degloving enables effective correction of complex Peyronie's deformities. Urology 2012;79:831-5.

70. Hudak SJ, Morey AF, Adibi M, et al. Favorable patient reported outcomes after penile plication for wide array of peyronie disease abnormalities. J Urol 2013;189:1019-24.

71. Chung PH, Scott JF, Morey AF. High patient satisfaction 
of inflatable penile prosthesis insertion with synchronous penile plication for erectile dysfunction and Peyronie's disease. J Sex Med 2014;11:1593-8.

72. Djordjevic ML, Kojovic V. Penile prosthesis implantation and tunica albuginea incision without grafting in the treatment of Peyronie's disease with erectile dysfunction. Asian J Androl 2013;15:391-4.

73. Rahman NU, Carrion RE, Bochinski D, et al. Combined penile plication surgery and insertion of penile prosthesis for severe penile curvature and erectile dysfunction. J Urol 2004;171:2346-9.

74. Kim DH, Lesser TF, Aboseif SR. Subjective patientreported experiences after surgery for Peyronie's disease: corporeal plication versus plaque incision with vein graft. Urology 2008;71:698-702.

75. Puri K, Hellstrom WJ. Long-term follow-up of the indications for manual modeling vs plaque excision/ grafting in men undergoing placement of inflatable penile prostheses for peyronie's disease. JOURNAL OF UROLOGY. LIPPINCOTT WILLIAMS \& WILKINS 530 WALNUT ST, PHILADELPHIA, PA 19106-3621 USA; 2004. p. 331.

76. Devine CJ, Horton CE. Surgical treatment of Peyronie's disease with a dermal graff. J Urol 1974;111:44-9.

77. Lue TF, El-Sakka AI. Venous patch graft for Peyronie's disease. Part I: technique. J Urol 1998;160:2047-9.

78. Pathak AS, Chang JH, Parekh AR, et al. Use of rectus fascia graft for corporeal reconstruction during placement of penile implant. Urology 2005;65:1198-201.

79. Akman T, Sanli O, Gurkan L, et al. Use of rectus fascia

Cite this article as: Anaissie J, Yafi FA. A review of surgical strategies for penile prosthesis implantation in patients with Peyronie's disease. Transl Androl Urol 2016;5(3):342-350. doi: 10.21037/tau.2016.04.04 graft for corporeal reconstruction during implantation of penile prosthesis in Peyronie's disease. In Abstracts 8th Congress of the European Society for Sexual Medicine; 2006:1.

80. Wilson SK, Carson III CC. Surgical straightening with penile prosthesis. Peyronie'S Disease. Current Clinical Urology,2007:249-58. Available online: http://link. springer.com/chapter/10.1007\%2F978-1-59745-161-1_23

81. Sansalone S, Garaffa G, Djinovic R, et al. Simultaneous penile lengthening and penile prosthesis implantation in patients with Peyronie's disease, refractory erectile dysfunction, and severe penile shortening. J Sex Med 2012;9:316-21.

82. Rolle L, Ceruti C, Timpano M, et al. A new, innovative, lengthening surgical procedure for Peyronie's disease by penile prosthesis implantation with double dorsalventral patch graft: the "sliding technique". J Sex Med 2012;9:2389-95.

83. Egydio PH, Kuehhas FE, Valenzuela RJ. Modified Sliding Technique (MoST) for Penile Lengthening with Insertion of Inflatable Penile Prosthesis. J Sex Med 2015;12:1100-4.

84. Egydio PH, Kuehhas FE. Penile lengthening and widening without grafting according to a modified "sliding" technique. BJU Int 2015;116:965-72.

85. Perito P, Wilson S. The Peyronie's plaque "scratch": an adjunct to modeling. J Sex Med 2013;10:1194-7.

86. Ostrowski KA, Dugi DD 3rd, Hedges JC, et al. Bone Saw for Calcified Peyronie's Disease Plaques. Urology 2015;86:415-6. 